\title{
Los alimentos y el imaginario de la comunidad perdida en la poesía chilena del siglo $\mathrm{XX}$
}

\author{
Food and Imagery of the Lost Community in \\ the 20th Century Chilean Poetry \\ Os alimentos e 0 imaginário da comunidade \\ perdida na poesia chilena do século XX
}

\section{Naín Nómez}

UNIVERSIDAD DE SANTIAGO DE CHILE, CHILE

Académico de Excelencia en la Universidad de Santiago de Chile. Ph.D. por

la Universidad de Toronto (Canadá). Entre sus últimas publicaciones se encuentran el libro Escrito en Rokha: Antología de Pablo de Rokha (Editorial de la Universidad de Talca, 2013), la antología de Nicanor Parra Un puñado de cenizas (Lom Ediciones, 2015), el libro de poemas Historias del reino vigilado (Lom Ediciones, 2018), y los artículos "Poesía de mujeres en Chile: voces del simulacro entre la dictadura y la transición" (en Casa que nunca ha sido extraña, editado por Milena Rodríguez, Peter Lang Publishing, 2017) y "Locas mujeres': aproximaciones a la poesía de Gabriela Mistral y sus contextos" (Ínsulas, 2018). Correo electrónico: nain.nomez@usach.cl

\section{Artículo de investigación}

Este artículo se enmarca dentro del proyecto DICYT No 031551ND de la Universidad de Santiago de Chile, titulado "Poesía chilena: modernidad, postmodernidad, sobremodernidad: transformaciones y mutaciones culturales" (2015-2017).

Documento accesible en línea desde la siguiente dirección: http://revistas.javeriana.edu.co doi:10.11144/Javeriana.cl22-44.aicp 


\section{Resumen}

El presente artículo incursiona en la poesía chilena del siglo $\mathrm{XX}$, a partir de la revisión del imaginario de los alimentos en su relación con las comunidades rurales de la zona central del país, que se representan como comunidades desaparecidas o perdidas, lo que implica así mismo la paulatina desaparición de las costumbres, las tradiciones y las identidades locales. Por otro lado, en los textos poéticos, el sistema alimentario del mundo urbano se representa como un espacio enajenado y extranjerizante, ligado a identidades fragmentadas y marginadas.

Palabras clave: poesía; comunidad perdida; identidad local; imaginario alimenticio

\section{Abstract}

The current article studies the20th century poetry in Chile by examining the relation between the food imageryand the rural communities, in particular those located in the central region of the country. These are represented as lost and vanished communities, which implies the gradual disappearance of customs, traditions and local identities. Additionally, in the poetic texts the urban food system is represented as an alienated and foreign space, linked to fragmented and marginalized identities.

Keywords: poetry; lost community; local identity; nutritional imaginary

\section{Resumo}

$\mathrm{O}$ presente artigo incursiona na poesia chilena do século $\mathrm{XX}$, a partir da revisão do imaginário dos alimentos na sua relação com as comunidades rurais da área central do país, representadas como comunidades desaparecidas ou perdidas, o que implica mesmo assim, o gradual desaparecimento dos costumes, tradições e identidades locais. Por outro lado, nos textos poéticos, o sistema alimentar do mundo urbano é representado como um espaço alienado e estrangeirizante, vinculado a identidades fragmentadas e marginadas.

Palavras-chave: poesia; comunidade perdida; identidade local; imaginário alimentar

RECIBIDO: 20 DE JUNIO DE 2017. ACEPTADO: 14 DE NOVIEMBRE DE 2017. DISPONIBLE EN LÍNEA: 28 DE DICIEMBRE DE 2018

\section{Cómo citar este artículo:}

Nómez, Naín. "Los alimentos y el imaginario de la comunidad perdida en la poesía chilena del siglo XX". Cuadernos de Literatura 22.44 (2018): 223-250. https://doi.org/10.11144/Javeriana.cl22-44.aicp 


\section{Una breve genealogía de la poesía chilena del siglo $\mathrm{XX}^{1}$}

De las rupturas de las vanguardias estéticas y políticas que relevaron los discursos fundamentales del arte mundial y latinoamericano entre los años veinte y treinta, quedaron en Chile, además de las imponentes figuras de Pablo Neruda, Pablo de Rokha y Gabriela Mistral, los ecos tardíos de los mandragoristas del año 38 (Braulio Arenas, Enrique Gómez Correa, Teófilo Cid) y la continuidad de algunos poetas epigonales, pero residuales y tardíos, como es el caso de Rosamel del Valle, Humberto Díaz-Casanueva, Eduardo Anguita, Omar Cáceres, Jorge Cáceres y Gustavo Ossorio, entre otros. Y si bien la obra de estos poetas fue importante, ya que marcaron un reciclamiento sostenido de los discursos anteriores con experimentaciones que dinamizaron ciertas líneas simbolistas, la lucha por la hegemonía poética empezó a darse con las nuevas promociones que pedían aire y vida cotidiana.

Esta especie de repliegue discursivo y temático frente a los cánticos trascendentes de la vanguardia, se desenvuelve con una intensa necesidad de comunicación con el mundo, que se acentúa con los llamados "poetas de la claridad", marcada, por un lado, por la publicación de Cancionero sin nombre de Nicanor Parra en 1937 y por la antología Ocho nuevos poetas chilenos, realizada por Tomás Lago en 1939. Entre los poetas nuevos figuraban, además de Nicanor Parra, Oscar Castro, Victoriano Vicario, Luis Oyarzún y Alberto Baeza Flores. Con las vanguardias aprendimos a entender la modernidad como parte de una obsesión por lo nuevo, lo contingente y lo transitorio; como una ruptura continua que tenía al frente la idea de un progreso indefinido, pero también como un fenómeno que acarreaba su propia decadencia y corrosión al cuestionar el reino de lo divino y desencantarse del mundo humano. Pero el exceso discursivo había terminado por esconder la realidad que se quería mostrar para quedarse solamente con el simbolismo exacerbado del lenguaje. Cuando Nicanor Parra en los años cincuenta, con gran intuición alude a la necesidad de religar el arte con la vida, está devolviendo al poeta moderno aquello que se propusieron Charles Baudelaire y Arthur Rimbaud en el origen de su fractura con el mundo burgués. La vida no era esa alienación del artista moderno separado de su origen, sino algo que venía de más lejos y que

1 Esta sección reitera y rescribe algunos planteamientos ya desarrollados por el autor en trabajos anteriores de 2004, 2006 y 2007 (ver obras citadas). 
había que rescatar desde el otro lado de la historia: el lado oscuro, obsceno, marginal, degradado.

Hay un contexto nacional e internacional al que no son ajenos artistas, ni escritores ni poetas, aunque no necesariamente incida en sus producciones. En el ámbito histórico de los cuarenta y los cincuenta, acontecimientos como la Guerra Fría y la dicotomía ideológica, los populismos latinoamericanos y la ruptura de la estabilidad política en Chile contrastan con hechos más positivos como el fin de la Segunda Guerra, la política democratizadora de los frentes populares, la política económica de un Estado que incentiva la industrialización, la aparición de nuevos partidos como Democracia Cristiana y el ascenso de los movimientos sociales. En los años cuarenta se reformula el modelo económico chileno, que tiene cada vez menos autonomía frente al capitalismo mundial, agudizando la crisis del Estado hacia 1955, cuando la inflación se desata y la economía se estanca. Mientras grandes sectores sociales reivindican sus derechos económicos y sociales (por ejemplo, el voto definitivo de las mujeres), los trabajadores urbanos pierden poder adquisitivo, la agricultura no crece y más de un tercio de los niños no asiste al colegio. La inflación llega en ${ }_{195} 6$ al $86 \%$, la más alta registrada hasta ese momento en la historia del país. En este ambiente los escritores polemizan y toman partido, preferentemente por posiciones de cambio y transformación social, a veces militando en partidos de centro o de izquierda, a veces como compañeros de ruta o simples testigos críticos. Muy poco después, en 1959, la revolución cubana provocará adhesiones y rechazos aún más radicales en las posturas críticas de los artistas y escritores chilenos.

El campo literario chileno y las posiciones de los autores dentro de él (autores, críticos, editoriales, periódicos, revistas, agentes, instituciones culturales, etc.) hacia mediados del siglo XX, son un campo en disputa en donde coexisten diversas tendencias, grupos y sensibilidades (Bourdieu). Viven y escriben poetas de viejo cuño nativista, criollista o modernista como Diego Dublé Urrutia, Jerónimo Lagos, Carlos Préndez Saldías y Daniel de la Vega, junto a poetas más jóvenes pero aún nostálgicos de un mundo rural y pueblerino en retirada como Alejandro Galaz, Hermelo Arabena Williams o Carlos Collins Bunster, o vates articulados a las coyunturas políticas como el caso de Juvencio Valle, Luis Merino Reyes, Olga Acevedo y Alberto Baeza Flores. La modernidad en crisis se reordena bajo nuevas formas sistémicas (capitalismo, imperialismo, transnacionalización, populismos, socialismos y comunismos diversos en 
Yugoeslavia, Italia y China, alternativas económicas regionales y continentales), que permiten retomar las utopías sociales en la historia, lo que repercute también en los discursos literarios. Esto se representa en Chile en los cantos apoteósicos y mitopoéticos de Pablo Neruda y Pablo de Rokha en los años cincuenta.

A partir de estos contextos, una parte importante de los nuevos poetas pretende clausurar el complejo entramado del imaginario vanguardista. Esa es la tarea que emprende Parra y que, desde distintas vertientes estéticas, acompañan y continúan poetas como Gonzalo Rojas, Enrique Lihn, Jorge Teillier, Delia Domínguez, Efraín Barquero, Armando Uribe, Alfonso Alcalde, Rolando Cárdenas, Stella Díaz Varín, Miguel Arteche, David Rosenmann-Taub, entre otros. Desde la obra temprana de Parra se pueden vislumbrar al menos tres posturas: 1) La del poeta que critica la urbe moderna desde un sitio marginal y degradado, que se vislumbra en textos como "El gato muerto", "La niña engañada" o "La niña testaruda" de Cancionero sin nombre, pero más claro en "Autorretrato" o "Los vicios del mundo moderno" de Poemas y antipoemas. 2) La del sujeto que ironiza su situación, construyéndose innumerables máscaras transitorias; aquí casi todos los poemas de los libros mencionados antes, y 3) La del poeta que se hace cargo del mito del origen perdido a partir de la imposibilidad del retorno y que está ya en el poema "Hay un día feliz", publicado en 1954. Esta última es la que nos interesa en esta presentación, porque se vincula con la poesía del Lar y la nostalgia por un mundo rural perdido, cuya fuente de reconstrucción es la memoria, a través de un repliegue afectivo frente a un mundo adverso. Sus representantes más visibles, dentro de sus diversidades y estéticas específicas, son Jorge Teillier, Efraín Barquero, Luis Vulliamy, Rolando Cárdenas, Alberto Rubio, Marino Muñoz Lagos, Pablo Guiñez, Delia Domínguez y en alguna medida también David Rosenmann Taub, Alfonso Calderón, Violeta Parra y Miguel Arteche. Estos últimos, aunque no se integran a las estéticas láricas, sí escriben un puñado de poemas que reflejan este sentimiento de retorno a una comunidad arcádica, que se representa como un paraíso perdido frente a las vicisitudes del proceso moderno. El poeta de raigambre lárica, contrario a sus antecesores ruralistas de comienzos del siglo XX (Augusto Santelices, Jorge González Bastías, Carlos Acuña, Jerónimo Lagos Lisboa o Carlos Préndez Saldías), representa una nostalgia del desarraigo de la infancia, pero sin retorno. Es un paraíso perdido que ni siquiera la memoria es capaz de retener, porque se convierte en pura imagen soñada. En 
este punto es necesario aclarar que el concepto de lo "lárico" se atribuye fundamentalmente a la obra de Jorge Teillier, aunque algunos de los otros poetas del periodo, como hemos señalado, se acercan a este tópico de una manera más tangencial y distanciada.

\section{El imaginario de los alimentos y la comunidad perdida en la poesía chilena moderna}

La alimentación como imaginario y metáfora de las relaciones sociales, políticas y económicas de una sociedad se despliega en todos los ámbitos de la vida humana, siendo el arte, como expresión central de la cultura, uno de los ámbitos donde el lenguaje alimenticio adquiere un papel relevante. En este sentido, la literatura y especialmente la poesía, han desarrollado históricamente una representación de los alimentos, que se fusiona con las maneras como los autores han visualizado su sociedad y las relaciones que establecen los sujetos para dialogar con ella. Para Claude Lévi-Strauss (410-432), la nutrición es la forma básica que caracteriza la cultura de cada grupo. A partir del análisis de una serie de culturas, el autor concluyó que el alimento en las comunidades humanas se ofrece en tres estados principales: crudo, cocido y podrido. Lo crudo sería el estado no marcado y tiene afinidad con lo asado y la cocina a la parrilla, que serían la primera técnica de transformación del alimento. Lo cocido es la transformación de lo crudo, y lo podrido su transformación natural. Esto da origen a una doble oposición: la de lo elaborado y lo no elaborado y la de la cultura versus la naturaleza. A estos elementos habría que agregar lo hervido, lo frito y lo ahumado, también más cerca de la cultura. Pero todo ello delimita un campo semántico desde fuera, es decir, de cada cultura en particular y de cada época singular, puesto que en ciertas circunstancias lo crudo y lo asado son también representaciones de sofisticación cultural. Para Mijaíl Bajtín en La cultura popular en la Edad Media y el Renacimiento, la idea del banquete o la gran comida popular plantea un hiperbolismo positivo y un tono triunfal y alegre, tal como apreciamos, por ejemplo, en textos de Pablo de Rokha o Pablo Neruda. Para ello, el autor se remite al texto de Rabelais, Gargantúa y Pantagruel (uno de los autores favoritos de De Rokha), analizando las imágenes del cuerpo grotesco durante el banquete y el motivo de la boca abierta y la deglución. En su estudio, Bajtín muestra hasta qué punto las imágenes de la alimentación se fusionan con el cuerpo y las marcas de la reproducción: fertilidad, crecimiento y alumbramiento. La absorción de alimentos en el banquete se relaciona con las fiestas 
y la imagen grotesca del cuerpo, pero también con la palabra y la sabia conversación: "en el comer... el cuerpo se evade de sus límites; traga, engulle, desgarra el mundo, lo hace entrar en sí, se enriquece y crece a sus expensas [...]. El hombre degusta el mundo, siente el gusto del mundo, lo introduce en su cuerpo, lo hace una parte de sí mismo" (253). El banquete rabelesiano que describe Bajtín, puede verse no solo en los poetas ya mencionados, sino que deriva hacia las instalaciones de varios poetas de los cincuenta, como veremos a continuación (Barquero, Rubio, Lihn, entre ellos). El planteamiento de Bajtín resulta sumamente válido para analizar la manera como los poetas de los cincuenta articulan la relación entre el trabajo y el comer colectivo, el "vínculo esencial con la vida, la muerte, la lucha, la victoria, el triunfo, el renacimiento" (253). Bajtín coincide con Pierre Mayol, para quien "el vino y el pan tienen su lógica propia, su verdad, su invencible aspiración a la superabundancia, el inherente matiz indestructible de alegría y de triunfo victorioso" (262; las cursivas son del autor). Mayol, quien escribe en conjunto con Michel de Certeau y Luce Giard los dos tomos de La invención de lo cotidiano (1980-1999), señala que: "hay dos alimentos que 'acompañan' la comida de comienzo a fin y se acomodan a cada momento de la serie: el pan y el vino... Son pues la base de la cocina; es en lo que debe pensarse en primer término antes de cualquier otra decisión gastronómica" (Tomo II, 87). Agrega que "mientras el respeto por el pan habla de los invitados, el vino tiene una marca social de destemplanza y celebración. En este sentido, el pan y el vino representan el sacrificio y la solidaridad, el reencuentro con la memoria, la celebración, las nupcias, el regocijo del encuentro (87-102). ${ }^{2}$ José Bengoa, por su parte, señala que en Chile "lo propio" está profundamente ligado a lo rural. Y añade:

Chile, al igual que muchas otras sociedades, posee la sensación de haber perdido parte de su identidad [...]. A ello se refiere el concepto de comunidad: algo que une a las personas fuera del mercado, un conjunto de significados que están implícitos en el sentido que se les otorga a las palabras, a los gestos, a los silencios aprendidos y a la capacidad de

2 El pan y el vino aparecen permanentemente en las obras de varios poetas de los cincuenta. Esto es singularmente relevante en Barquero (con un libro titulado El pan y el vino), en Lihn, en Alcalde, en Arteche, entre otros. Además, están en muchos textos de poetas anteriores como Mistral, De Rokha y Neruda. 
producir -y reproducir- nuevos gestos, nuevos significados comprendidos por todos. (21-23)

Y remata: "la cultura de la modernización compulsiva se opone a la cultura de la identidad" (25). El autor paraleliza las identidades rurales desarrolladas durante el siglo XX con algunos proyectos poéticos que las incluyen:

Algún día entenderemos el mestizaje rural que se fue formando en largos depósitos en el secano costero, en los valles internos, en esa mitad del país, en esas provincias del sur agrícola. Entenderemos el Parral de Neruda, el Elqui de Gabriela, el Chillán de la Violeta, de Nicanor y de don Roberto, el Licantén de De Rokha... (35)

Para insistir más adelante:

Quizá el desafío consista en retomar críticamente la tarea de los De Rokha. El gran proyecto que hace De Rokha es tratar de urbanizar la cultura popular, la civilización de la chingana, la cultura rural, lanzarla a la universalidad, no negarla. (38)

Resulta también indudable para nosotros, que el rescate de los alimentos que desarrollan además varios de los poetas que escriben en los cincuenta, se relaciona con este miedo de perder la identidad, lo que produce un sentimiento de nostalgia por el mundo de un Chile rural ya inexistente, soslayado o marginado.

En varios textos, ${ }^{3}$ Magda Sepúlveda ha reiterado que hay un grupo de poetas que trabaja las comidas y bebidas como patrimonio local, en el que se "destaca la enseñanza de los preparados y las maneras en la mesa con su protocolo codificado, como sucede con los platos y brebajes de la zona central" ("Nachi, cazuela, antropofagia y veneno" 157). Agrega que "los poetas de este grupo atribuyen propiedad y originalidad local a ciertas comidas, de forma tal que la gastronomía se transforma en un bien en disputa entre los saberes del campo y la ciudad...y constituye una defensa

La autora ha señalado que en la poesía chilena el signo culinario forma cuatro grandes grupos: 1) La construcción de comunidades alrededor de la comida; 2) El patrimonio provinciano y/o rural como defensa frente al mundo urbano (tendencia que privilegiamos en este trabajo); 3) Los deseos caníbales entre diversas subjetividades, y 4) los linajes relacionados con el hambre y el sacrificio humano ("Ñachi, cazuela, antropofagia y veneno" 151-166; "Para una entrada en la imaginación poética" 199-213). 
contra la homogeneidad centralista que impulsa lo moderno" (159). Cita los casos de poetas como Pablo Neruda, Pablo de Rokha, Violeta Parra, Nicanor Parra, Jorge Teillier, Alberto Rubio, José Ángel Cuevas, en quienes "los alimentos se convierten en atributo de pertenencia patrimonial" (158). Nuestro trabajo busca ahondar en esta línea que se hace mayoritaria en la poesía de los cincuenta.

Desde los inicios de la república, la relación campo-ciudad ha sido analizada, interpretada y tematizada desde diferentes ángulos y la posición de los alimentos en esta situación no ha escapado de la discusión general. Así, cuando Andrés Bello llama a "las jóvenes naciones" a cultivar la tierra para nutrir a las familias y al Estado, cambiando la fertilidad de la naturaleza por labor agrícola, utiliza la poesía en función de la economía y la política. En su poema "Silva a la agricultura de la zona tórrida" de 1826 , continuación descriptiva de la "Alocución a la poesía" de 1823, aparece la agricultura supeditada al tono épico de la silva neoclásica en que se personifica la humanización de lo natural. Al alabar los frutos americanos, el poeta chileno-venezolano hacía un fervoroso llamado a cultivar la tierra y a nutrir a las familias y al Estado, cambiando la fecundidad natural por la labor agrícola propia de la república. Su llamado a transformar la alimentación natural a través del trabajo, se proyecta hacia el desarrollo de una unidad política de reconciliación, que tiene en mente la idea de progreso, y de una incipiente modernización dentro del proceso de la modernidad en ciernes. El poema, con toda su carga de demolición republicana hacia las antiguas formas de subsistencia, representa una de las primeras expresiones en América que desplaza la alimentación "natural" y la fecundidad espontánea de los frutos a través del trabajo hacia un intento modernizador que, a su juicio, logrará la paz, la virtud, la unidad política y la reconciliación de todas las naciones. Con reminiscencias de Virgilio, Luciano, Lucrecio y Horacio, sus ídolos clásicos, Andrés Bello desarrolla una alabanza a la riqueza alimenticia de América, estableciendo una primigenia identidad de lo propio, cuya finalidad es convocar a los americanos a aunar fuerzas para aprovechar este espacio "idílico" que naturaliza la satisfacción de las necesidades básicas. En una segunda instancia, el poema muestra los peligros que conlleva la falta de moral y de integración representados por "el odio pestilente ciudadano", haciendo un contraste entre el mundo rural y el mundo de la ciudad, donde priman la guerra, la ambición, el lujo, los amores ilícitos y la falta de ejercicio. En el tercer momento de este poema, el sujeto pide romper el yugo ciudadano y volver 
al campo, pero un campo cultivado donde el trabajo humano (agricultura, siembra) permita darles a los seres humanos, alegría y libertad, humanizando el mundo natural. El poema culmina con un llamado a la integración del hombre americano, la conversión de zona en nación y la defensa de la vida simple ligada a la labranza y la templanza, que haga ciudadano al soldado sin el vicio de las ciudades.

Por lo tanto, las representaciones alimenticias existen desde los inicios de la poesía moderna nacional y, como ya vimos en Bengoa, sus principales referencias culturales han estado y siguen estando en el campo:

Hasta el día de hoy, se podría afirmar, lo urbano no se ha impuesto a lo rural en el ámbito de la cultura. Las formas de la vida rural siguen siendo el ideal de la "vida buena" para una enorme proporción de los ciudadanos, que viven en ciudades muchas veces saturadas. (13)

Entre los poetas anteriores a la vanguardias que escriben entre $1895 \mathrm{y}$ 1916, aproximadamente, que fluctúan entre el modernismo y el mundonovismo (para algunos autores el postmodernismo), las comidas y bebidas son ampliamente representadas, ya sea por medio de una simbología continuadora de los elementos preciosistas y exotistas del modernismo, ya sea como una búsqueda de la identidad con el mundo rural que se desgaja del neoclasicismo de Bello. En el primer caso, podemos citar por ejemplo a Abelardo Varela (1871-1903) en su poema "La novia", del que evocamos un fragmento: "Cuando en la copa del licor preciado/ que el misterio del bien y el mal encierra,/ iba su alma a calmar vagos anhelos,/ cual rico aroma de un cristal guardado/ que triza el aire, sin tocar la tierra/ se elevó, blanca nube, hacia los cielos" (Nómez, Antología crítica 142). En este texto, la novia se equipara a la evanescencia del vino y de la nube para unir lo ideal y lo terrenal y hacer trascendente el sueño erótico del sujeto. Desde la perspectiva que nos interesa, la del mundo rural, ya se plantea en varios poemas la amenaza de un mundo metropolitano que se hace cada vez más masivo, anónimo y amenazante para lo que se entiende por "identidad cultural". Carlos Acuña (1886-1963), en "Flauta rústica" se proyecta en el goce alimenticio, aludiendo al retorno a la heredad, origen y fuente de nostalgia y alegría: "Mojaré mi fauce seca/ con la leche del corral;/ yantaré del trigo rubio/ que las mozas lavarán/ y la harina de la piedra,/ en mis labios blanquearé/ en esta hambre y sed benditas/ con que tomo mi a heredad" (353). La representación de la falta de amor, por el contrario, alude en sus poemas a la sequedad del vergel rural: "los 
sarmientos están secos;/ ni del racimo el negror,/ ni las hojas de la parra/ muestran su fresco verdor;/ los ojitos -graos de uva-/ se secaron de mi amor" ("Vendimia" 355). De la nostalgia de lo rural, surgen líneas críticas que muestran la marginalidad y el abandono de la vida en las grandes metrópolis. Un poeta que describe en forma vívida la miseria de la ciudad y la carencia alimenticia, es Carlos Pezoa Véliz (1879-1908). En el poema "El organillo" leemos: “Pobre peón! En otros días/ la tierra era de los viejos;/ de ellos, el parrón, sus guías,/ las bestias, sus aparejos./ Cuando la tierra era buena:/ cuando no había patrones/ que hicieran siembras de pena/ y vendimia de pulmones" (272). Texto en que, como señala Bengoa, se idealiza un mundo campesino sin patrones explotadores y con una concepción comunitaria de la tierra, que probablemente no existió. En Pezoa Véliz, no hay gran diferencia entre el mundo humano y el animal dentro de la ciudad donde coexiste el perro vagabundo con el campesino desplazado y convertido en peón/proletario.

En ese momento, la oposición campo/ciudad no tiene la relevancia que adquiere con el crecimiento de las ciudades desde comienzos del siglo XX hasta nuestros días, pero el refugio en una arcadia rural y su vinculación con los alimentos, sigue siendo un tópico recurrente en la poesía moderna, incluyendo a algunos de nuestros vanguardistas más relevantes. Pablo de Rokha y Pablo Neruda son los casos ejemplares, pero en Gabriela Mistral (1889-1957) el imaginario alimenticio no solo es importante sino fundamental. En ella, los alimentos esenciales se ligan con los grandes mitos andinos y las divinidades indígenas, devolviéndoles su carácter ancestral y su origen mestizo. Hay en la producción mistraliana al menos dos acercamientos a las materias alimenticias. La primera alude a las materias básicas como el agua y la sal en su relación con el origen humano, para entregar un aprendizaje de reconocimiento. A eso se agregan alimentos creados por el cultivo humano, como el maíz, los frutos, el trigo y las actividades del comer y el beber. Aquí se busca una relación de respeto hacia los alimentos y la cultura que los creó. En una segunda instancia se promueve el espacio del cultivo local, la huerta, así como la necesidad de recobrar el carácter litúrgico de las culturas originarias. En ese sentido, su poema "El pan" de Tala (1938) deviene una genealogía del alimento que se hace alabanza, liturgia, homenaje y celebración religiosa, donde el pan, personificándose, hace metonimia de la unión trascendente que la poeta busca en la naturaleza, para sacarla del exotismo de la modernidad y reintegrarla a una comunidad imaginada: "Dejaron un 
pan en la mesa,/ mitad quemado, mitad blanco" (Mistral, Poesía y prosa 132). El pan es dejado sobre la mesa y se independiza de cualquier origen o fuente. Pero desde allí inicia un camino histórico que es reproducido por un sujeto que lo reconstruye desde su propio conocimiento: "Huele a mi madre cuando dio su leche/ huele a tres valles por donde he pasado:/ a Aconcagua, a Pátzcuaro, a Elqui,/ y a mis entrañas cuando yo canto" (132). Madre, naturaleza del norte del país (valle y montaña) y la intimidad esencial de la sujeto (entrañas) están "memorizadas" en el olor del pan. La sujeto dialoga con el pan ("no hay nadie tampoco en la casa"), pero el pan deja de ser objeto para transformarse en un sujeto con cuerpo, historia, alma: "con su cuerpo me reconoce/ y con el mío yo reconozco" (132). A partir de una historia común, la sujeto del poema establece una relación comunitaria con el pan que es otro y el mismo ("nuevo y como no visto"), activando la memoria ("el mismo pan en cien hermanos"), los encuentros y desencuentros ("después lo olvidé, hasta este día/ en que los dos nos encontramos") y la abertura de la historia personal y colectiva: "los dos en este silencio humano,/ hasta que seamos otra vez uno/ y nuestro día haya acabado" (133). Como ha reiterado Bengoa:

La identidad colectiva es hija legítima de la nostalgia, se construye en torno a ella... La identidad colectiva se organiza en torno al rito y al mito, a la noción del tiempo que acompaña a la nostalgia, a la visión "subjetiva" del tiempo. La identidad cultural es una suma de depósitos añorados por los habitantes presentes de esta sociedad que miran el pasado con una cierta nostalgia. Es por ello que las identidades son irracionales, obedecen a recuerdos, creencias, afectos, nemotecnias colectivas que hacen de un grupo humano un todo con sentido, con pasado y con futuro. (13)

Así como en el poema, las diferentes formas de conocer y reconocer el pan van dando cuenta de un proceso de memoria y aprendizaje que recorre espacios, tiempos, amistades, deseos y ternuras. Las transformaciones, los olvidos, los reencuentros que la sujeto rememora mientras voltea la miga del pan, mitad quemado y mitad blanco (cuerpo mestizo) y pellizcado, comunican al lector una experiencia cultural integradora. Personificado, el pan se hace materia humanizada para reubicarse en una unión con la naturaleza y a la vez sacar a la sujeto de su lugar inhumano para reintegrarla a una comunidad imaginada. 
En De Rokha y Neruda, los alimentos y las comidas se convierten en simbolizaciones de las identidades populares nacionales, especialmente en el caso de las comunidades rurales y pueblerinas. De manera distinta, ambos poetas hacen un catálogo o inventario de lugares, personajes y actividades ligados al alimento o a la comida a través de elogios, alabanzas, vinculaciones geográficas, representaciones y personificaciones, que van dando cuenta también de la pluralización de identidades del pueblo chileno y latinoamericano. En el caso de Neruda, las materias alimenticias son cantadas en un tono optimista; y no las muestra en su estado natural, sino transformadas a partir del trabajo, señalando su origen, su producción, su estado de domesticación y finalmente el proceso de intercambio y consumo. Es lo que notamos por ejemplo en "Los frutos de la tierra" de Canto general y los libros de las odas: "Oda al pan", "Oda a la sal", "Oda al maíz", "Oda a la papa", "Oda a la cebolla", "Oda al aceite"; "Oda a la alcachofa", "Oda al tomate" y, especialmente, en la "Oda al caldillo de congrio". En esta última, se muestra el desplazamiento del pescado desde el mar hasta la olla, pero también se realiza una receta perfecta a partir de la cual el sujeto apostrófico conmina a su auditorio/lector a encontrar en su poema las "esencias" de Chile. En casi todos los poemas-alimentarios de Neruda, la relación con la tierra y el mundo campesino es primordial. En el caso de Pablo de Rokha su "Epopeya de las comidas y bebidas de Chile" es ya un clásico de la poesía chilena. Junto a otros poemas como "Campeonato de Rayuela", "La posada de don Lucho Contardo", "Rotología del poroto" y "Los borrachos dionisíacos" conforma el tópico de lo que he llamado "lo nacional popular". Igual que Neruda, el poeta se plantea la presencia de los alimentos como una búsqueda identitaria que intenta romper el estereotipo de lo propio con un ruralismo apatronado, relacionándolo con una construcción personal a partir de lo "vivido" y "experimentado" como poeta-testigo y narrador. Los textos son un catálogo de lugares y comidas que convierten el comer y el beber en un acto litúrgico y único que caracteriza pueblos, zonas y personajes concretos y abstractos, entre los cuales asoma la interlocución del lector y la experiencia del sujeto que dialoga gozosamente con su placer y el de los receptores. Aquí, como en Neruda, la comida es el soporte de la identidad cultural y mantiene sus raíces en el mundo rural. 
Identidad rural y alimentación comunitaria:

Violeta Parra, Efraín Barquero y Jorge Teillier

Como señalamos antes, en los años cincuenta del siglo XX, cuando las diferencias entre campo y ciudad se hacen más antagónicas, los alimentos y su origen rural se resignifican como paradigmas de un mundo perdido y es por ello que nos detendremos especialmente en los poetas de ese momento. Un puente importante entre los poetas adscritos a la búsqueda del origen de este periodo es Violeta Parra (1917-1967), cuyas décimas hechas a solicitud de su hermano Nicanor, describen su autobiografía en poemascanciones que relatan su vida, la historia de su familia y las reflexiones que las historias le van suscitando. Como ella misma señala, su canto se vincula con el folclore de Chile, y lo separa en canto a lo humano, canto a lo divino, cuecas, tonadas, parabienes, danzas campesinas, cantos con influencia europea, esquinazos y cantos de Navidad. En medio de estas diversas formas del canto popular, la poeta incluye el campo de los alimentos, ya sea de manera directa o a través de metáforas emocionales y reflexivas. En las descripciones, se trata no solo de mostrar la realidad rural en que vivió gran parte de su vida, sino también de representar la abundancia y la escasez alimenticia de los lugares que conoció, con el carácter festivo de la copla popular en octosílabos. Así es como se describe una fiesta en casa de los abuelos de manera pormenorizada: "La cena ya se sirvió/ en una mesa largucha,/ en cada plato, una trucha,/ pa'la trucha, un botellón,/ pa'la botella un copón,/ pa'la copa una galleta;/ encima'e una servilleta/ con un plateado cubierto; /como el pescado está muerto/ le asoma ají por la jeta" (Parra 37). La descripción del ambiente y los alimentos continúa con el aperitivo, los postres, un nuevo plato de estofado y el escenario de los comensales, el servicio y las diferencias sociales que representan las formas de alimentarse:

Sirven el aperitivo

p'alentar el apetito, mistelas y pastelitos, después vendrá el bajativo.

Ya se ven menos altivos

en el salón elegante, porque el vino es abundante en el banquete d'estilo ¡qué pensarán los pililos, comiendo guata picante!... 


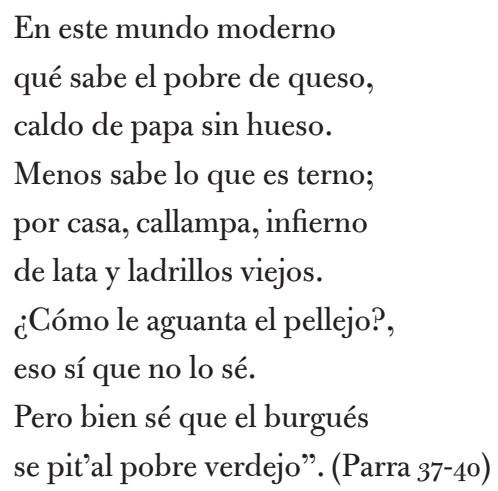

Otros poemas incorporan el tema a través de la experiencia del viaje por tren: "Pasamos por Longaví,/ llegamos a Miraflores/ como chirigües cantores;/ abrimos el cocaví./ Los pasajeros allí,/ comieron pollito fiambre,/ después vi de los alambres/ que s'iban y se venían,/ y de repente venía/ de pájaros, un enjambre" (46). Una tercera representación que se reitera en la poeta, es la de la reflexión sobre los avatares de la vida en donde se incluye la imagen alimenticia: "Hay más: en los hospitales/ pasa cura'o un enfermo,/ le traen en lindo termo,/ el zumo de los parrales;/ el preso pagando males/ en un cuartel felizcote,/ de alcohol, un botellonzote/ con el qu'está barnizando,/ un trago de cuando en cuando/ le cruza por el cogote" (56). En Violeta Parra, la comida está signada por la amplificación gozosa del mundo rural y su contracara urbana de pobreza y hambre.

En algunos de los poetas del periodo, los alimentos adquieren el carácter de un imaginario del reencuentro (con la tierra, con la familia, con el origen, con la niñez, con un colectivo perdido o imaginado) y la identificación con una comunidad rural soñada. Tal vez el más emblemático es el de Efraín Barquero (1931), hermanado con Jorge Teillier por la raigambre de su poesía con un origen mítico, pero del cual se separa a través de la instauración de los símbolos de la amistad, el compañerismo, el amor y la colectividad en el aquí y el ahora. En esta búsqueda, los alimentos pasan a ser mediaciones esenciales entre yo y el otro, entre el yo y la sociedad. En el poema "Tierra china" (Antología) se dirá: "El hombre solo vive cuando recupera su semilla/ lo demás es este largo cautiverio de la luna/ esta vieja manera de morir lejos de aquellos que nos guardaron/ un lugar junto al pan impenetrable" (162). Lo mismo ocurre en el poema "El pan":

Es blanco el pan, es familiar como la madre;

pero él cuando lo encuentra después de un día de siega 
o después de hacer un surco en el pecho del sol...

lo descubre negro como un resto de desgracia o un incendio,

lo tacta duro como si su dolor ya lo hubiera forjado,

lo gusta amargo como si lo hubiera avinagrado su fiebre,

lo siente triste como si lo llorara su cuerpo envejeciendo,

lo calla avergonzado, como si todos sus hijos lo pidieran,

lo deja, tembloroso, como si se tocara su carne maltratada. $(23)^{4}$

El relato de la historia del pan aparece aquí como el relato metonímico de la explotación humana con sus dolores y sus diferencias sociales, pero también está la referencia a la historia personal de un sujeto que se desdobla para enfrentarse a sí mismo en la memoria de la penuria familiar.

En libros publicados como La mesa de la tierra (1998), la pertenencia y el arraigo que se busca se simbolizan en la mesa que es el lugar donde se comen los alimentos y también la tierra que los produce. En poemas como "El brindis" y "El alimento", la mesa aparece como el lugar de encuentro entre vivos y muertos, entre el pasado y el presente, estableciendo una confluencia del tiempo y el espacio que idealiza la materia y metaforiza los actos cotidianos. En el poema "El cuchillo enterrado", el cuchillo se convierte en el símbolo de un puente entre el intercambio de la vida (cortar el pan para los otros) y el tema de la muerte-regeneración (el sacrificio cristológico) representado por la sangre que fluye del corte:

Coge el viejo cuchillo ennegrecido

por los años y roído por un gran remordimiento...

Lo coge y lo entierra mirando a todos lados

sobre un gran pan con un chasquido sordo

como si atravesara la palma de una mano extendida.

Lo empuña de nuevo y se hace un corte en el muslo

que embebe con un trozo de ese mismo pan

como si fuera su comida desde ahora.

Y prueba la sangre de dos heridas abiertas

-la suya y la que nunca se conoce en los otros. (23)

4 El poema "Tierra china" pertenece al libro El viento de los reinos de 1967, mientras que el poema "El pan" es de su primer libro publicado en 1954, que se titula La piedra del pueblo. 
El cuchillo es también la articulación entre el recuerdo de lo inmemorial y el arraigo en un presente que exorciza la enemistad y el odio y que busca el reencuentro familiar y cultural, como en "La mesa servida":

Si arrancas el cuchillo del centro de la mesa

y lo entierras en el muro a la altura del hombre,

estás maldiciendo el pan con su semilla,

estás profanando el cuchillo que usa tu padre

para rebanarse la mano, para que la sangre sea más pura.

Y los hijos se reconozcan. Y no se oculten de sus hermanos...

No es una mesa, es una piedra. Tócala en la noche...

Tócala y pídele que vuelva a ser ella misma

porque si no existiera, no podríamos tocar

el sol con una mano y la luna con la otra.

Y comeríamos a oscuras como los ratones el grano. (9)

Así es como la materialidad de la necesidad alimenticia (pan, semilla, mesa) se convierte en un símbolo de la convivencia humana, al igual como la sangre es la señal del sacrificio de unos por otros. Esto se ratifica en un libro titulado El pan y el vino (2008), que, como señala Pierre Mayol, son el $a$ priori de la comida. El autor agrega que, si el pan representa la dureza de la vida y del trabajo, como el monumento para conjurar el sufrimiento y el hambre, el vino se vincula a la fiesta como marca social, como celebración relacionada con el exceso y la locura (De Certeau, Giard y Mayol 88). En el libro de Barquero, los alimentos son el medio a través del cual se da la solidaridad entre el visitante y el visitado, lo que de nuevo ocurre en la mesa-casa-tierra-vida. El pan y la mano que lo sirve se mezclan con su origen, el grano y la semilla cuya genealogía se cuenta en el poema "La cáscara/ el grano" del mismo libro: "El cuarto donde guardaban la semilla era oscuro/ y me cuesta mucho encontrarlo en mis recuerdos./ Era un cuarto como dentro de otro aun más pequeño/ donde se oía día y noche/ desprenderse la cáscara del grano" (40). La hora del pan y la hora del vino aparecen como esenciales para el ser humano cuando se enfrenta al sacrificio, a la solidaridad o a la traición. Pan y vino consolidan el instante de la celebración, las nupcias, el regocijo del encuentro que fija el instante y que permite remontarse a los orígenes:

$\mathrm{Al}$ comer frente a otro el mismo

bocado/ nos damos cuenta que

no podríamos hacerlo sino en una 
mesa donde todos somos iguales/

donde todos tenemos el mismo

porte/ donde nos confundimos con

el vapor de la comida/ con el halo

de nuestro aliento/ al ofrecer el pan

y el vino a los comensales tú haces

que su semilla no se pudra en la tierra. (20)

Axis mundi de todo llamado y de toda respuesta, la hora del pan y la hora del vino aparecen como parte integral del ser humano enfrentado al sacrificio, a la solidaridad y la traición: "siente que es él mismo un bocado/ donde el pan no se endurece" (35). Pan y vino son también elementos litúrgicos para un reencuentro con la memoria que sostiene la genealogía humana, el padre, la madre y "el calor del único fuego sin ceniza" (40). En su último libro, Pacto de sangre (2009), los alimentos se ligan a una liturgia de regeneración que articula comunidad y comunión a través del sacrificio. A partir de las figuras de la castellana y la india, el poeta desarrolla un movimiento que es un proceso de aprendizaje y reconocimiento entre dos culturas que se comunican de diversas maneras, entre las cuales la alimentación y la comida son fundamentales. En este poemario, como en otros anteriores de Barquero, el cuchillo representa un símbolo fundamental de la unión o la separación de los seres humanos. En el poema "El cuchillo de piedra" leemos: "Aún no puedo saber por qué esconde tanto el cuchillo/ no sólo de mí sino de todas las miradas extrañas./ Como si fuera el primero que consagraron sus dioses/ cuando decretaron el sacrificio de los animales... Ella también parece esconderse muy adentro de sí misma/ ahí mismo donde sus dioses ocultaron el cuchillo de los hombres" (29). En este libro los símbolos de lo alimenticio son la base de la comunicación y el reconocimiento del otro: enterrar granos en el jardín, beber en la vertiente, el agua de la lluvia, beber leche de las piedras o el sabor del barro. El acto final del sacrificio del cordero une a ambas mujeres a través de la sangre del animal en un acto que se opone al canibalismo y a la antropofagia del dominio, de la represión, de la tortura o de la desaparición del otro:

Ambas mujeres renacen de nuevo al ver el mismo cordero

que degolló la india

convertido en otro aún más hermoso.

Entonces se preparan a celebrar con los demás

Algo entrañable 
algo que tienen en común con los animales

al dar a luz

al dar la primera leche

al dar su cuerpo en alimento. (83)

De esta manera, el poeta desarrolla un movimiento que circula de la castellana a la india y de la india a la castellana desde una diversidad de ritos, pasajes, ceremonias, formas de encuentro que van desde la extrañeza del otro al reconocimiento, de la exclusión a la inclusión, desde la indiferencia a la humanización del otro y en donde los alimentos y sus utensilios ocupan una simbolización esencial y ancestral: el cuchillo, la piedra, los granos, el agua, el pan, el vino y finalmente la sangre que al beberse une y hermana.

En el caso de Jorge Teillier (1935-1996), como han señalado diversos críticos (entre ellos el propio autor), su obra descansa en la tradición de la representación lárica (poesía del Lar, del Origen, de la Frontera), aunque trasciende este arraigo en una serie de haces temáticos que se abren en otras direcciones. Sus poemas arrancan del recuerdo "ingenuo" y la nostalgia por la pérdida de un mundo ancestral que representa el paraíso de la infancia, que paulatinamente se desintegra y se convierte en pura imagen soñada. Se trata de postular un tiempo de arraigo cuyo cronotopo está en un espacio rural incontaminado, que se preserva en el mito o en la memoria. En 1965, en el texto "Los poetas de los lares. Nueva visión de la realidad en la poesía chilena", el poeta señalaba:

Frente al caos de la existencia social y ciudadana los poetas de los lares... pretenden afirmarse en un mundo bien hecho, sobre todo en el del mundo del orden inmemorial de las aldeas y de los campos, en donde siempre se produce la misma segura rotación de las siembras y cosechas, de sepultación y resurrección [...]. De ahí también la nostalgia de los "poetas de los lares", su búsqueda del reencuentro con una edad de oro, que no se debe confundir sólo con la de la infancia, sino con la del paraíso perdido que alguna vez estuvo sobre la tierra... (Prosas 26$)$

En su poesía existe el sur mítico y lluvioso de Pablo Neruda, pero desrealizado por una creación verbal en donde los lugares de provincia se tiñen de referencias melancólicas y simbólicas que se hacen universales. El poeta aparece como el sobreviviente de un paraíso perdido, como el soñador vi- 
sionario de una época dorada de la humanidad que conserva a través de los tiempos el mito y la imagen esencial de las cosas: casa, tierra, árbol (Ignacio Valente, 1975). Pero el recuerdo ingenuo e incorruptible que se recupera por medio de la memoria se trasciende solo momentáneamente y culmina en su paulatina desintegración. Frente a ello, se buscan las huellas perdidas para acceder al lugar maravilloso de donde venimos. A través del recuerdo, la realidad cotidiana se hace visible y se recupera. Pero ella solamente sobrevive en los lugares del hallazgo, constituido por los residuos del pasado y los espacios secretos y ocultos. De acuerdo con Giordano ("La poesía de Jorge Teillier"), el poeta recupera dos momentos estéticos: el de la infancia y el del recuerdo. En el poema "Bajo el cielo nacido tras la lluvia", esta felicidad pasajera se hace evidente: "Pues siempre podremos estar en un día que no fue ayer ni mañana, / mirando el cielo nacido tras la lluvia/ y escuchando a lo lejos/ un leve deslizarse de remos en el agua" (108).

Los alimentos aparecen en Teillier, bajo la forma de dones de la naturaleza que están en ese illo tempore al alcance de la mano para comerlos, contemplarlos o gozarlos como los frutos o los brotes del árbol. Pero también forman parte de la armonía universal de un mundo no contaminado por el tráfago de la modernidad: la chicha de manzana, la harina tostada, las manzanas. El alimento está allí al alcance de la mano, como en el paraíso, listo para ser consumido, y en Teillier fundamentalmente las manzanas y la chicha de manzana, que proliferan en su región y su infancia: "La sangre de las manzanas/ ilumina la sidrería" (Los dominios perdidos 28); “¿Quién recogerá esas manzanas/ donde aún brilla un sol de otra época?" (29); "Pasea por mi cuarto/ como la sombra desnuda/ de los manzanos en el muro" (48); "Mi padre tenía un gran manzanar./ Había abundancia de manzanas.../ No se sufría hambre" (137). Y en otro poema: "Había abundancia de manzanas,/ crecían por todas partes,/ los árboles se agachaban hasta el suelo por la abundancia de las frutas./ No se sufría hambre./ El que tenía ganas comía harina tostada y tomaba chicha..." (117). En general, los alimentos naturales aparecen en sus poemas como un entorno maravilloso que enfatiza la armonía, la solidaridad, el amor, la amistad, lo bucólico del paisaje. Así, "Esa noche oí caer las nueces desde el nogal" (20); "yo llenaba esas manos de cerezas, esas/ manos llenaban mi vaso de vino" (21); "y los almendros no quieren pensar/ en sus negras raíces" (22); "Los pájaros se comían las migas/ que sembraba para señalarte el camino" (47); "la sangre blanca de un cerezo/ era el anuncio de nuevas puertas" (132); "Y ahora / voy a pedir otro jarrito de chicha con 
naranja" (144); "yo oía a los mapuches pregonando cochayuyo" (161), etc. Esta visión armoniosa del mundo, cercana a la representación romántica, se distancia más del objeto alimenticio que en los textos de Barquero, aunque a veces también forma parte del intercambio amoroso o la amistad, como en el poema "Sentados frente al fuego": "Yo llenaba esas manos de cerezas, esas/ manos llenaban mi vaso de vino".

A veces, las menos, algunas formas elementales del alimento se convierten en Teillier en metáforas del desarraigo y de la vida presente, como en el final del poema "Despedida": "Me despido de la memoria/ y me despido de la nostalgia/ -la sal y el agua/ de mis días sin objeto" (39), donde sal-memoria y agua-nostalgia se convierten en los símbolos de una carencia actual: de un hambre ancestral y simbólica no saciada. En general, en esta poesía, los alimentos se presentan en forma pura, como parte de la armonía perenne de ese universo destruido para siempre por el proceso moderno. Las manzanas puestas a guardar, el licor de guindas que preparó la abuela, el olor a café, el maqui de los mendigos, el racimo de uvas, el primer vino que ofrecieron, la caída de las nueces desde el nogal, el olor a pan recién amasado, beber un vaso de cerveza, las mazorcas asoleándose en los techos, el blanco vaso de aguardiente, son todos gestos petrificados en el magnesio fotográfico de una atmósfera imaginada arquetípica, que repite una y otra vez su evocadora imagen de los "dominios perdidos". Estos alimentos que "adornan", adjetivan o encuadran el gesto de reconstrucción de la memoria mitificada, solo adquieren un carácter activo en el país de los sueños, donde el poeta convierte el pasado en la rememoración de los amigos muertos, aquellos que se dispersaron "como el polvillo de los duraznos en los dedos" ("Señales" 52) o como proyecto futuro: "en mis sueños vienes/ atravesando las estaciones.../ y al despertar veré que el pan sobre la mesa/ tiene un resplandor más grande..." (54). Proyecto que a veces adquiere un carácter visionario: "para hablarles del tiempo en que la tierra/ se multiplicará con los panes y los peces/ y será de verdad para todos" (99).

\section{Del origen alimentario a la modernidad degradada:}

\section{Alberto Rubio y David Rosenmann-Taub}

Alberto Rubio (1928) y David Rosenmann-Taub (1927), de diferentes maneras, recurren a imágenes rurales para incursionar en el mundo del origen, también como una crítica frente al proceso de la modernidad. En el caso de la poesía de Rubio, la elaboración de la comida induce a recuperar los lazos con una comunidad rural que se focaliza en los familiares, los ami- 
gos, los conocidos y todos aquellos a quienes reúne alrededor de la mesa. Un rasgo fundamental de su obra es la manera como logra la personificación de los alimentos, a partir de la visión ingenua del niño que recupera el objeto en su estado prístino. El uso del oxímoron y la extensión de los sentidos interpelan a los alimentos, de una manera tan novedosa que estos nos penetran por todas partes y desde todas las direcciones. En ese sentido, en su poesía no se habla de la infancia ni de los orígenes, sino que el sujeto que habla y el sujeto que lee devienen infancia y origen. Así, en el poema "El almuerzo" de su único libro publicado La greda vasija (1952), que citamos in extenso por su carácter paradigmático, respecto a lo que señalamos, se nos dice:

El almuerzo zapallo nos denuncia.

Su esencia nos traspasa, y en éxtasis quedamos.

heridos y dorados los zapallos,

abren su corazón a un zapallo apetito.

Sus brazos son vapores aromados

desplegándose al aire.

Los zapallos invitan, heridos y dorados.

El aire se derrite de apetito.

Infinito me vuelvo, denunciado

de esencia zapallera, almorzador zapallo. $(27)^{5}$

En este poema, el aura del zapallo nos envuelve con una suma de cualidades que no solo incita nuestros sentidos (olor, vista, sabor, color, gusto, tacto, oído, sinestesias), sino que se cualifica (denuncia, éxtasis, heridos, doradas, vapores, apetito) y se personifica hasta simbolizar el almuerzo como una hipérbole de la fruición estética y sensible. Todo esto en medio de un bosque de aliteraciones, onomatopeyas, anáforas y repeticiones que dan origen a una poesía que integra reiteradamente lo natural con lo humano.

En la poesía de Rubio todo el ámbito natural contribuye a relevar la comunión del ser humano con el otro a través de la mesa familiar y la alimentación. En "Mesa del alba", la mesa del desayuno se alegra con el reencuentro de los seres queridos, el diálogo y una integración natural que es celebración gozosa de la vida:

5 En este trabajo citamos la reedición del libro realizada por la Universidad de Concepción en el año 2000. 
La mesa en la mañana me espera con su silla...

un hombre al desayuno se lanza con sus dientes...

Es pájaro la lengua de ese hombre sentado.

Y conversa con otro que a su lado se sienta...

Y así nace el gorjeo matinal de la casa.

¡A dónde brilla un sol que es comedor brillante,

de la cocina vino la vaporosa taza,

desde el mismo horizonte con su día fragante! (21)

Después de la soledad, el desayuno permite el diálogo, que se escenifica como un diálogo de pájaros, con el brillo del sol, la taza vaporosa y el día fragante. Este goce sensual, pleno e integral del sujeto con la naturaleza y la comida, se repite en el poema "¿Colmado de comida revolcarme en la hierba!" donde la sensualidad corporal y espiritual permea todo el texto. Aquí "comida", "hierba", "sol amarillo", "tierra", "cielo" y "suelo" son indistinguibles de las sensaciones del propio sujeto que se siente en plenitud: "colmado de comida", "revolcarme en la hierba", "entrecerrar los ojos como en acabamiento", "párpados", "sentir la tierra", "quedarme dormido", "rotundamente vivo". Esta simbiosis entre la sensualidad de los sentidos y su reproducción en el mundo natural se focaliza en la noción de la "luz" que aparece en la primera y segunda estrofa para reiterarse acumulativamente en la tercera, iluminando su carácter de gozo exacerbado. En el poema "Sandial" como en "El almuerzo", todos los sentidos del sujeto se hunden en el goce sensual de la sandía, a través de cuyo calado se interna en la memoria de la infancia para recuperar olores y sabores, que incluyen el recuerdo de la madre y la fruición estética del poema:

Por un hondo camino me aproximo a la historia que en la honda sandía me sangra frescamente.

Es como hacer alegre calado en la memoria recordar a mi madre sandía hundidamente.

Y me hundo profuso en la roja sandía, y a mi madre me encuentro, filial en el regazo, sentada en el profundo y maduro mediodía: ¡todo en senos sandiales el verano le abrazo! (49)

De este modo, la visión de la sandía en el recuerdo del sujeto evoca la visión del seno materno con su frescura, sangre filial y calor, abriendo y 
cerrando el calado de la memoria, para volver a encontrarse con la madre: "encontrarme a mi madre... madurada en frescura que, sandía ;se cierra!" (49). De este modo, el calado en la madre-sandía-memoria permite representar el sandial como el cronotopo que recupera el goce orgiástico de la infancia rural y asimismo la comunidad perdida.

En la poesía de David Rosenmann-Taub (1927), la nostalgia del paraíso perdido es también evidente como soporte de un lenguaje primigenio que se intenta reconstruir en forma insistente y obsesiva para sostener la precariedad de la vida. En esta tarea, de exorcizar un presente poblado por el dolor y el vacío, el sujeto de los poemas busca el imaginario de un país más allá en cuya utopía convergen el pasado y el futuro y que se llena con el jardín de la infancia, el amor filial o el reencuentro con la inocencia perdida. En la primera edición de su libro Cortejo y epinicio de 1949, los utensilios y objetos de la cocina adquieren vida propia para interpelar a los sujetos, al mismo tiempo que sirven para rememorar el lugar de la infancia. En el soneto XLVIII "La taza de café, la cafetera", la enumeración caótica de los utensilios va fermentando una acumulación de recuerdos, que intensifica las sensaciones de la infancia, hasta impregnar los sentidos en el presente y proyectarlos hacia el futuro:

La taza de café, la cafetera, el vapor que me entibia el esqueleto, la fragante sartén, el amuleto tiznado, la albahaca, la sopera,

el roto lavaplatos, la nevera como una madrugada y el coqueto jarrón multicolor, el parapeto lleno de tarros, azafrán y acelgas...

Todo lo mío claro regresa a tu silvestre estera. En tu vapor, sin fin me desvanezca cuando llegue la hora en que no crezca oh dichosa cocina, cuando muera... (118)

El vapor de la cafetera ensoñada hacia o desde el pasado, sirve para enhebrar el futuro inevitable desde un presente en que la añoranza de la cocina familiar recobra con fuerza la arcadia perdida. Arcadia que los 
utensilios de cocina y el vapor de la tetera rememoran e integran con el momento final, el del desvanecimiento del sujeto en la muerte. Esta caracterización de los utensilios de la cocina y el comedor, que evocan un tiempo pretérito en un ámbito rural, personificados y con vida propia, se repite en otros poemas como el VIII, que lleva como subtítulo "El gato coge a una mariposa". En un ambiente nocturno con ciertos visos tenebrosos, los objetos perciben el drama solitario del gato atacando la mariposa, como testigos impotentes del drama:

las alas a la rastra.

Inmensa mariposa, toda gris ligereza, navío, ante arañazo, despreocupado, gris, te tronchas y tu vuelo rebota disonante...

El gato te mastica: a las sillas recorre un nervioso crujido, las copas tintinean roncamente en el trinche, las servilletas gritan.

$\mathrm{Y}$ en espantoso acuerdo el comedor se angustia:

el gato te mastica: oh chirrido espantoso.

Es un lloro estridente, es un lamento eterno

de cucharas, manteles, platos, alcuzas, vasos... (37)

La extrañeza del texto es provocada por la caracterización humanizada que adquieren los objetos en sus actitudes de impotencia frente al drama del cual son mudos testigos, como si fueran personas. Esta antropomorfización de los objetos es recurrente en la producción poética del autor y saca sus textos del armónico e idílico ámbito rural de otros poetas del periodo, para enhebrarlos con un presente en que se advierte la presencia ominosa de la muerte, lo que puede apreciarse en los poemas "IV", "Cosecha en sosiego", "Moi vivant", "Canción de cuna", "La lentísima", "Diálogo sepulcral", entre otros.

\section{Casi colofón}

Hay otros poetas que inician su producción en los cincuenta y que mantienen este repudio al proceso devastador de la modernidad y su reflejo más evidente, el multitudinario, masivo y degradado mundo urbano, incorporando las representaciones alimenticias como un elemento central de su adhesión a los valores de una comunidad perdida.

Es el caso de Luis Vulliamy, Rolando Cárdenas, Fernando González Urizar, Marino Muñoz Lagos, Emma Jauch, Pablo Guiñez, Carlos Ruiz 
Zaldivar o Alfonso Calderón. En mucho de sus textos, lo propio se hibrida en los espacios, los acontecimientos, los personajes y los alimentos como una mixtura que delinea las identidades nacionales y regionales, en contra de la corriente dominante del progreso indefinido y la modernización a ultranza. Poemas que representan la angustia frente al proceso avasallador de las modernizaciones que hace desaparecer el universo "idílico" del campo y específicamente del mundo rural de la zona central de Chile. Bengoa señala que:

La nostalgia es el recuerdo positivamente valorado. Es por ello que se lo desea revivir. Al no ser posible, se produce dolor. La nostalgia es un sentimiento doloroso de pérdida, de la inevitabilidad del tiempo. (10)

\section{Y agrega:}

[La nostalgia rural] es una paradoja. A pesar de ello, es un elemento central de la cultura chilena. En este país, en su cultura e identidad, en el inconsciente colectivo, la ruralidad tiene una importancia central. La historia social, la historia cultural de Chile, no es comprensible sin su ruralidad... Algún día entenderemos el mestizaje rural que se fue formando en largos depósitos en el secano costero, en los valles internos, en esa mitad del país, en esas provincias del sur agrícola... ¿Acaso no nos reconocemos en esos paisajes, en esos pasillos, en esos espacios, en esos dolores, en ese sueño perdido de ver desde la ventana las tumbas de nuestros padres y abuelos? (31-37)

Y la rememoración nostálgica no puede dejar afuera los alimentos, que se constituyen en símbolos que condensan el encuentro con la memoria, "los encuentros entre figuras (ollas, platos, alimentos, mesas, humos, temperaturas, recetas, cuerpos) y significados (cariño, cuidado, recuerdos, hogares, malestares, desencantos y soledades)... en su invitación al sentido" (Hernández 48). En los poetas, las formas alimentarias y la comida son también señales, signos, símbolos, metáforas y sentidos de ese mundo perdido que se pretende recuperar y mantener en un presente donde el lazo social se ha extraviado y en un futuro desgarrado por la soledad y la destrucción de la colectividad. En su retorno a los orígenes, los poetas de los cincuenta intentan recuperar el mito de la comunidad perdida ligada a los ritos y liturgias más ancestrales de la alimentación. Como recalca Barquero:

Bebes el vino que nos acerca a los

hombres/ en tus ojos aparece la 
primera mirada con que se mira todo

dejándolo en su sitio/ así la flor brota

de nuevo donde la recuerda la abeja/

el hombre pasa su mano sobre su

copa servida acariciando su aroma/

después se toca la frente tratando de

acordarse de algo/ de quién nos

acordamos cuando probamos el vino

en silencio/ al regocijarnos con la comida

y la bebida comprendemos por un

segundo lo eterno/ lo más inexplicable. (El pan y el vino 48)

\section{Obras citadas}

Bajtín, Mijaíl. La cultura popular en la Edad Media y el Renacimiento.

Barcelona: Seix Barral Editores, 1974. Impreso.

Barquero, Efraín. Antología. Santiago de Chile: Lom Ediciones, 200o. Impreso.

Barquero, Efraín. El pan y el vino. Santiago de Chile: Lom Ediciones, 2008. Impreso.

Barquero, Efraín. La mesa de la tierra. Santiago de Chile: Lom Ediciones, 1998. Impreso.

Barquero, Efraín. Pacto de sangre. Talca: Editorial Universidad de Talca, 2009. Impreso.

Bello, Andrés. Antología de Andrés Bello. Comp. Pedro Grases.

Caracas: Ministerio de Educación Nacional, 1969. Impreso.

Bengoa, José. La comunidad perdida. Ensayos sobre identidad y cultura: los desafíos de la modernización en Chile. Santiago de Chile: Ediciones Sur, 1996. Impreso.

Bourdieu, Pierre. Las reglas del arte. Génesis y estructura del campo literario. Barcelona: Editorial Anagrama, 1995. Impreso.

De Certeau, Michel, Luce Giard y Pierre Mayol. La invención de lo cotidiano 2. Habitar, cocinar. México: Universidad Iberoamericana, 1999. Impreso.

De Rokha, Pablo. Epopeya del fuego. Antología. Ed. Naín Nómez. Santiago de Chile: Editorial de la Universidad de Santiago, 1995. Impreso.

Giordano, Jaime. "La poesía de Jorge Teillier". Poesía chilena (19601965). Santiago de Chile: Ediciones Trilce, 1996. 114-126. Impreso.

Hernández, Marisela. "Deleites y sinsabores de la comida y el comer: situando el tema". Atenea 496 (Primer semestre de 2007): 41-54. Impreso.

Ibáñez Langlois, José Miguel (Ignacio Valente). Poesía chilena e hispanoamericana actual. Santiago de Chile: Nascimento, 1975. Impreso.

Lévi-Strauss, Claude. Mitológicas III. El origen de las buenas maneras en la mesa. México: Siglo XXI, 1997. Impreso. 
Mistral, Gabriela. Poesía y prosa. Ed. Jaime Quezada. Caracas: Biblioteca Ayacucho, 1993. Impreso.

Neruda, Pablo. Obras completas. Tomo I-II-III. Buenos

Aires: Editorial Losada, 1957-1973. Impreso.

Nómez, Naín. Antología crítica de la poesía chilena. Tomo IV.

Santiago de Chile: Lom Ediciones, 2006. Impreso.

Nómez, Naín. "Identidad rural y comunidad mestiza: algunas notas sobre las comidas y bebidas en la poesía chilena". Comidas bastardas. Gastronomía, tradición e identidad en América Latina. Ed. Ángeles Mateo del Pino y Nieves Pascual Soler. Santiago de Chile: Editorial Cuarto Propio, 2013. Impreso.

Nómez, Naín. "La poesía de los cincuenta: aproximaciones a una modernidad en disolución". Taller de Letras 34 (mayo 2004): 85-96. Impreso.

Nómez, Naín. "La poesía de los cincuenta en Chile y España: escorzo y aproximaciones". Campo de Agramante. Revista de Literatura 7 (Primavera-Verano, 2007): 85-101. Impreso.

Nómez, Naín. "Sobre El pan y el vino de Efraín Barquero. Por una liturgia de la solidaridad". Atenea 498 (Segundo Semestre de 2008): 143-151. Impreso.

Parra, Violeta. Décimas. Barcelona: Editorial Pomaire, 1976. Impreso.

Rosenmann-Taub, David. Cortejo y epinicio. Santiago de Chile: Cruz del Sur, 1949. Impreso.

Rubio, Alberto. La greda vasija. $2^{\text {a }}$ edición. Concepción: Cuadernos Atenea, 2000. Impreso.

Sepúlveda Eriz, Magda. "Ñachi, cazuela, antropofagia y veneno: para una entrada en la imaginación poética alimentaria chilena". Comidas bastardas. Gastronomía, tradición e identidad en América Latina. Eds. Ángeles Mateo del Pino y Nieves Pascual Soler. Santiago de Chile: Editorial Cuarto Propio, 2013. Impreso.

Sepúlveda Eriz, Magda. "Para una entrada en la imaginación poética alimentaria chilena". Revista Chilena de Literatura 88 (Segundo Semestre, 2014): 199-213. Impreso.

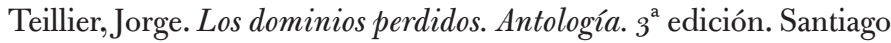
de Chile: Fondo de Cultura Económica, 1996. Impreso.

Teillier, Jorge. Prosas. Santiago de Chile: Editorial Sudamericana, 1999. Impreso. 